NBER WORKING PAPER SERIES

\title{
IMPROVING THE ACCURACY OF ECONOMIC MEASUREMENT WITH MULTIPLE DATA SOURCES: THE CASE OF PAYROLL EMPLOYMENT DATA
}

\author{
Tomaz Cajner \\ Leland D. Crane \\ Ryan A. Decker \\ Adrian Hamins-Puertolas \\ Christopher Kurz \\ Working Paper 26033 \\ http://www.nber.org/papers/w26033 \\ NATIONAL BUREAU OF ECONOMIC RESEARCH \\ 1050 Massachusetts Avenue \\ Cambridge, MA 02138 \\ July 2019
}

We thank ADP for access to and help with the payroll microdata that underlie the work described by this paper. In particular, this work would not have been possible without the support of Jan Siegmund, Ahu Yildirmaz, and Sinem Buber. We are grateful for discussions with Katharine Abraham, Borağan Aruoba, Simon Freyaldenhoven, Erik Hurst, Gray Kimbrough, Alan Krueger, Norman Morin, Matthew Shapiro, John Stevens, David Wilcox, Mark Zandi, and seminar participants at the Federal Reserve Board, the Federal Reserve Bank of Cleveland, ESCoE Conference on Economic Measurement, the BLS, NBER CRIW meetings, the Bank of England, and the 2018 ASSA meetings. The analysis and conclusions set forth here are those of the authors and do not indicate concurrence by other members of the research staff, the Board of Governors, or the National Bureau of Economic Research.

NBER working papers are circulated for discussion and comment purposes. They have not been peer-reviewed or been subject to the review by the NBER Board of Directors that accompanies official NBER publications.

(C) 2019 by Tomaz Cajner, Leland D. Crane, Ryan A. Decker, Adrian Hamins-Puertolas, and Christopher Kurz. All rights reserved. Short sections of text, not to exceed two paragraphs, may be quoted without explicit permission provided that full credit, including $@$ notice, is given to the source. 
Improving the Accuracy of Economic Measurement with Multiple Data Sources: The Case of Payroll Employment Data Tomaz Cajner, Leland D. Crane, Ryan A. Decker, Adrian Hamins-Puertolas, and Christopher Kurz NBER Working Paper No. 26033

July 2019

JEL No. C53,C55,C81,C82,J11,J2

\section{ABSTRACT}

This paper combines information from two sources of U.S. private payroll employment to increase the accuracy of real-time measurement of the labor market. The sources are the Current Employment Statistics (CES) from BLS and microdata from the payroll processing firm ADP. We briefly describe the ADP-derived data series, compare it to the BLS data, and describe an exercise that benchmarks the data series to an employment census. The CES and the ADP employment data are each derived from roughly equal-sized samples. We argue that combining CES and ADP data series reduces the measurement error inherent in both data sources. In particular, we infer "true" unobserved payroll employment growth using a state-space model and find that the optimal predictor of the unobserved state puts approximately equal weight on the CES and ADP-derived series. Moreover, the estimated state contains information about future readings of payroll employment.

\section{Tomaz Cajner}

Federal Reserve Board 20th Street and C Street, NW

Washington, DC 20551

tomaz.cajner@frb.gov

Leland D. Crane

Federal Reserve Board 20th Street and C Street, NW

Washington, DC 20551

leland.d.crane@frb.gov

Ryan A. Decker

Federal Reserve Board 20th Street and C Street, NW

Washington, DC 20551

ryan.a.decker@frb.gov
Adrian Hamins-Puertolas

Federal Reserve Board

20th Street and C Street NW

Washington, DC 20551

Adrian.B.Hamins-Puertolas@frb.gov

Christopher Kurz

Board of Governors of the Federal Reserve System 20th and C Streets NW

Mail Stop 82

Washington, DC 20551

christopher.j.kurz@frb.gov 


\section{Introduction}

Economists and statisticians are increasingly confronted with new data sources, often produced by private companies as part of their business operations, that may be useful for economic research and measurement. These new data hold promise for advancing economic measurement and understanding, but their use raises many questions. How are new, alternative data different from traditional surveys and censuses? How are we to assess their reliability? How should multiple disparate data sources be synthesized to produce the best possible estimates?

We seek to answer these questions in the context of measuring payroll employment. In particular, we use data from a private payroll provider-ADP-to build an index of U.S. private payroll employment, similar in spirit to the Current Employment Statistics (CES)

survey. While the CES survey is carefully conducted and uses an extremely large sample, it still suffers from significant sampling error and nonresponse issues. The ADP-derived employment indexes are based on a sample that is roughly the same size as the CES sample, so it is plausible that pooling the information from ADP with that from CES would reduce sampling error and increase our understanding of the state of the labor market at a given time.

Previous work by Cajner et al. (2018) describes the construction of weekly and monthly aggregate employment series based on ADP's weekly payroll microdata. Their aggregate series (referred to as ADP-FRB) are designed to be an independent signal about labor market conditions rather than solely an attempt to forecast monthly BLS employment figures. However, Cajner et al. (2018) do indeed find that the timeliness and frequency of the ADP payroll microdata improves forecast accuracy for both current-month employment and revisions to the BLS CES data.

In this paper we further compare the ADP-FRB index to existing, high-quality government estimates and find encouraging results. The ADP-FRB index, and state-space estimates derived from it, provide information about future CES estimates in real time, including at 
the start of the Great Recession. In addition, we integrate benchmark employment data and compare the ADP-FRB benchmark revisions with the CES benchmark revisions. While the CES and ADP-FRB series are both prone to significant sampling and non-sampling error, the BLS Quarterly Census of Employment and Wages (QCEW) is generally considered the "final word" for annual employment growth because of its comprehensive administrative source data. Consequently, we benchmark the ADP-based series to the QCEW on an annual basis. The benchmarking procedure is broadly similar to CES benchmarking and ensures that year-to-year changes in ADP-FRB are governed by the QCEW, while higher-frequency changes, and the period after the most recent benchmark, are mostly a function of the ADP data. ${ }^{1}$

Existing work on using nontraditional data sources for economic measurement typically takes official government data as the source of truth, at all frequencies. For example, the monthly National Employment Report (ADP-NER) series published by ADP are constructed with the goal of predicting the fully revised CES data. ${ }^{2}$ In this paper we take a different approach by recognizing that both CES and ADP-FRB employment are subject to non-negligible measurement error and by using the Kalman filter to extract estimates of unobserved "true" employment growth from observations of both series.

Our baseline model assumes that true U.S. employment growth follows a persistent, latent process and that both the CES and ADP-FRB estimates are noisy signals of this underlying process. Standard state-space tools allow us to estimate the latent process and the observation error associated with each series. We find that the optimal predictor of the unobserved state, using only contemporaneous information, puts approximately equal weight on the CES and ADP-FRB series. This finding is not necessarily surprising, as the ADP sample covers roughly the same fraction of private nonfarm U.S. employment as the CES sample (about 20 percent), so the sampling errors ought to be of roughly similar magnitudes. We

\footnotetext{
${ }^{1}$ Benchmarking illustrates an essential role that government statistics play even when there is significant value in nontraditional data sources.

2 Mastercard's SpendingPulse, which attempts to forecast U.S. retail sales, is another example.
} 
also show that the smoothed state estimate, as constructed in real time, helps forecast future values of CES. Throughout, we focus on the role of these privately generated data as a complement to existing official statistics. While there is no substitute for official statistics in terms of consistency, transparency, and scientific collection methods, official numbers do have limitations that alternative data sources can address.

The paper proceeds as follows. Section 2 reviews the related literature. Section 3 describes the process of creating ADP-based employment indexes and lays out both the strengths and the inherent limitations of measuring nationwide payroll employment with ADP data. In section 4 we compare the annual ADP-FRB employment estimates to the official benchmarks, discuss the role of the birth-death model in the official estimates, present a case study of the usefulness of alternative employment data during the Great Recession, and show the efficacy of the ADP-FRB estimates in predicting fully revised CES payroll employment numbers. Section 5 introduces the state-space model that combines the information from both the ADP-FRB and CES-based estimates and provides evidence that the combined state improves our understanding of current and future payroll gains. Section 6 concludes.

\section{Related Literature}

Ours is not the first paper to make use of ADP payroll data. Several papers study the National Employment Report (NER), ADP's publicly available monthly estimate of U.S. payroll gains constructed jointly with Moody's Analytics. Importantly, NER estimates are derived from a model including not only ADP microdata but also other contemporaneous and lagged indicators of U.S. economic activity. The existing literature finds that the NER moves closely with CES (Phillips and Slijk, 2015) and has some ability to forecast CES, though it does not appear to improve forecasts based on other available information, such as existing consensus forecasts (Gregory and Zhu, 2014; Hatzius et al., 2016).

As noted above, we do not use the NER but instead focus on the ADP microdata. A number of recent papers explore these data. Cajner et al. (2018) analyze the representative- 
ness of ADP microdata (relative to CES and QCEW) and construct an ADP payroll index that can improve forecasts of CES; we employ that index in the present paper. Ozimek, DeAntonio and Zandi (2017) use ADP's linked employer-employee microdata to study the negative effect of workforce aging on aggregate productivity growth. Grigsby, Hurst and Yildirmaz (2019) study wage rigidity in the same data, finding that the high-frequency microdata can be useful for shedding light on a key business cycle question. Cho (2018) uses ADP microdata to study the employment and wage effects of the 2009 American Recovery and Reinvestment Act.

Our approach in the present paper is different from those above in that we explicitly investigate the usefulness of ADP as a supplement to CES data for tracking the underlying state of the labor market. In this respect, our work is inspired by Aruoba et al. (2016) who note difficulties in assessing the growth of aggregate output in real time given limitations on the comprehensiveness and timeliness of GDP measures. Two independent measures of GDP exist-the commonly reported expenditure-side approach and the income-based approach — and both are prone to measurement errors arising from various sources. Aruoba et al. (2016) combine the two measures using a state-space framework, recovering an underlying state of output growth which they label "gross domestic output." We follow this general approach with a focus on employment rather than output.

More broadly, a growing literature seeks to extract macroeconomic-relevant insights from alternative data sources. This topic is too broad to adequately summarize here, but we will provide some representative citations. Regarding labor markets, Hershbein and Kahn (2018) and Cajner and Ratner (2016) work with online job postings, while Antenucci et al. (2014) use social media data to predict UI claims. Inflation is another area of active research, with Cavallo and Rigobon (2016) and Goolsbee and Klenow (2018) using large databases of online prices. Gallin et al. (2018) use detailed real estate data to develop measures of housing wealth. Aladangady et al. (2016) use high-frequency data on credit card (and other card) transactions to study retail sales. The present paper adds to this (incomplete) list of uses of 
"big data" in macroeconomics. In addition, there is a large econometrics literature on working with high-dimensional data; see Stock and Watson (2002), Bernanke, Boivin and Eliasz (2005), Giannone, Lenza and Primiceri (2017) among many others. While our application is low-dimensional, with two observation series and one state process, we view the integration of detailed, alternative data with high-dimensional time series methods as a promising area of future work.

\section{Data}

This paper primarily uses three data sources: ADP microdata, the Current Employment Statistics (CES) survey, and the Quarterly Census of Employment and Wages (QCEW). Before turning to the ADP microdata in Section 3.1, it is useful to briefly lay out the relevant features of the CES and the QCEW.

The CES is the main source of monthly employment information in the United States. It is published by the BLS a few days after each reference month and is based on a stratifiedsample survey of about 500,000 private establishments covering 23 percent of all U.S. private employees. ${ }^{3}$ The CES asks each respondent for the count of employees who worked for pay in the pay period including the 12th of the reference month. Aggregate CES employment growth is a (weighted) average of the growth reported by units that respond for two or more consecutive months, plus a residual adjustment for establishment birth and death.

While the CES is a very large survey, it is still based on a sample and subject to sampling and non-sampling error (as discussed further below). In contrast, the QCEW, also maintained by the BLS, is a near-census of employment covered by unemployment insurance and serves as the sampling frame for much of the CES as well as the target for the annual benchmark of the CES. The main drawback of the QCEW is that the data are collected quarterly and published with a lag of two quarters. Thus, while the QCEW has negligible

\footnotetext{
${ }^{3}$ See https: //www.bls.gov/web/empsit/cestn.htm. Note that the CES contains data for total nonfarm payroll employment, but here we focus only on private payroll employment, excluding government employment to be consistent with the reliable scope of ADP.
} 
sampling error, it is of limited use to real-time decision makers. In addition, the QCEW is subject to various sources of non-sampling error. ${ }^{4}$ Nevertheless, we follow CES in using the QCEW for reweighting the ADP microdata and as a benchmark target.

\subsection{Structure and Representativeness of the ADP Microdata}

ADP provides human capital management services to firms, including payroll processing. Processing payroll for a client firm involves many tasks, including maintaining worker records, calculating taxes, and issuing paychecks. The structure of the microdata is determined by the business needs of ADP. ADP maintains records at the level of payroll account controls (PAC), which often correspond to business establishments (but may sometimes correspond to firms) as defined by the Census Bureau and the BLS. Each PAC updates their records at the end of each pay period. The records consist of the date payroll was processed, employment information for the pay period, and many time-invariant PAC characteristics (such as an anonymized PAC identifier, NAICS industry code, zip code, etc.). PAC records include both the number of individuals employed ("active employees") and the number of individuals issued a paycheck in a given pay period ("paid employees"). Active employees include wage earners with no hours in the pay period, workers on unpaid leave, and the like. Paid employees include any wage or salary workers issued regular paychecks during the pay period as well as those issued bonus checks and payroll corrections. In this paper we focus exclusively on active employment, having found that it is substantially less volatile, more closely resembles officially published aggregates, and performs better in forecasting exercises, though we plan to further investigate the active/paid distinction in the future. ${ }^{5}$

The data begin in July $1999 .{ }^{6}$ In terms of frequency, the files we use are weekly snapshots of individual PAC records, taken every Saturday since July 2009 (snapshots were taken semi-

\footnotetext{
${ }^{4}$ For a detailed analysis of measurement challenges in CES and QCEW, see Groen (2012).

${ }^{5}$ One topic for further investigation is exactly why active employment performs better than paid employment. It is possible that double counting due to the inclusion of payroll corrections, reimbursements, and bonuses adds noise to paid employment as measured in the ADP data. See Cajner et al. (2018) for further discussion.

${ }^{6}$ When accessing the microdata, we follow a number of procedures to ensure confidentiality. Business names are not present in the data we access.
} 
monthly between May 2006 and June 2009 and monthly before May 2006). Each snapshot contains the most recent pay date for each PAC, the relevant employment counts, and the other information described above. As few firms regularly process payroll more than once per week, the weekly snapshots provide a comprehensive history of PAC-level employment dynamics.

Several important differences between ADP payroll microdata and the QCEW and CES data exist in terms of pay frequency, region, establishment size, and industry composition: ${ }^{7}$

- Pay Frequency: The composition of businesses by pay frequency in the ADP data is roughly comparable to the population estimates available. In the ADP microdata, PACs reporting biweekly payroll frequency are somewhat more common, and those reporting weekly pay are somewhat less common, than in the official BLS data.

- Region: ADP data provide reasonable geographic representation of the country as a whole.

- Size: While the ADP data include businesses of all sizes (in terms of employment), ADP PACs generally tend to be larger than U.S. establishments. The ADP PAC size distribution marks a middle ground between the CES sample and the QCEW universe, with relatively more employment in small units compared with the CES sample. Notably, however, ADP has significantly more employment in mid-sized units than does CES, with a distribution that looks reasonably similar to QCEW.

- Industry Composition: Compared with both the CES sample and the QCEW universe, the ADP sample modestly overweights manufacturing employment and slightly overweights employment in services. Trade, transportation, and utilities employment is underweighted in the ADP data, while the weight of construction employment in ADP is similar to the CES sample, but both ADP and the CES sample underweight construction employment relative to QCEW.

\footnotetext{
${ }^{7}$ These composition differences are covered in detail by Cajner et al. (2018), which also provides additional detail on the construction of the indexes covered in section 3.2.
} 


\subsection{Series Construction}

The process of transforming the raw data to usable aggregate series is complex. Here we provide a brief, simplified explanation of the process. The interested reader may refer to Cajner et al. (2018) for details.

Each week, we calculate the weighted average growth of employment at PACs appearing in the data for two consecutive weeks. The restriction to "continuers" allows us to abstract from changes in the size of ADP's client base: as long as client turnover is random, the growth rate of continuers will be a valid estimate of aggregate growth (of continuers). Growth rates are weighted by PAC employment and further weighted for representativeness by size and industry. We use QCEW employment counts by establishment size and two-digit NAICS as the target population. Formally, let $w_{j, t}$ be the ratio of QCEW employment in a size-industry cell $j$ to ADP employment in cell $j$ in week $t$, let $C(j)$ be the set of ADP businesses in cell $j$, let $e_{i, t}$ be the employment of the $i^{\prime}$ th business, and let $g_{i, t}=\frac{e_{i, t}-e_{i, t-1}}{e_{i, t-1}}$ be the weekly growth rate of business $i .{ }^{8}$ Aggregate growth is estimated as

$$
g_{t}=\frac{\sum_{j=1}^{J} w_{j, t-1} \sum_{i \in C(j)} e_{i, t-1} g_{i, t}}{\sum_{j=1}^{J} w_{j, t-1} \sum_{i \in C(j)} e_{i, t-1}}
$$

Cumulating the weekly growth rates across time yields a weekly index level for employment. Our focus in this paper is on monthly estimates. We calculate the monthly index as the average of the weekly index for each month, weighting by days to account for partial weeks in each month. ${ }^{9}$ Monthly averaging smooths through the weekly volatility, and the results in Cajner et al. (2018) suggest that averaging improves performance relative to pointin-time methods more similar to the CES. The monthly index is seasonally adjusted using

\footnotetext{
${ }^{8}$ For weighting, we use March QCEW employment values for each year. For years where the March QCEW has not been released, we use the last available March QCEW. While we could allow QCEW values to vary quarterly or monthly, the shares are slow moving and thus this change would not significantly alter the results.

${ }^{9}$ For example, if a calendar week has four days in January and three days in February, our weighting by days procedure proportionally attributes the weekly employment to both months.
} 
the X-12 algorithm.

Figure 1 displays the seasonally adjusted ADP-FRB series (black line) along with the indexed CES estimate (red line). Importantly, the growth rate of the (weighted) ADP-FRB series is very similar to the CES, and the business-cycle frequency fluctuations are very closely aligned. Moreover, this ADP-FRB series does not incorporate any of the benchmarking discussed below, so nothing forces it to resemble CES. It is also evident that the ADP-FRB series is volatile, and much of the month-to-month variation does not appear to be related to the monthly swings in the CES data. We interpret this finding as evidence that both series are contaminated with measurement error, which can plausibly be attenuated by modeling the series jointly. For reference, Figure 1 also shows the ADP-FRB unweighted series, which does not correct the ADP size-industry distribution. Clearly, the unweighted series has a markedly different trend growth rate, though it shares the qualitative business-cycle frequency behavior of the others. ${ }^{10}$

\subsection{Strengths and Weaknesses of Different Types of Payroll Employment Data}

Perhaps the most important issue when analyzing the quality of a dataset is its representativeness. Obviously, the QCEW data have a clear advantage here because these data represent population counts. ${ }^{11}$ In contrast, CES and ADP estimates are sample based. As with CES, our ADP samples are adjusted with weights that are meant to make the estimates representative of the United States, but the weighting does not solve all issues. In the case of ADP, an important sample selection issue exists because only the firms that hire ADP to manage their payrolls show up in the ADP data. In the case of CES, the data are based on a probability sample of establishments, but as the response rates are only about 60 percent (Kratzke, 2013), this can introduce a potential sample selection issue as well.

\footnotetext{
${ }^{10}$ While we do not directly use the weekly ADP-FRB series in this paper, we view these high-frequency measurements as a promising topic for future research on, for example, natural disasters. The weekly series are discussed in more detail in Cajner et al. (2018).

${ }^{11}$ Note, though, that there is a small scope discrepancy between QCEW on the one hand and CES/ADP on the other hand: about 3 percent of jobs that are within scope for CES/ADP estimates are exempt from UI tax law. For more detail, see https://www.bls.gov/news.release/cewqtr.tn.htm.
} 

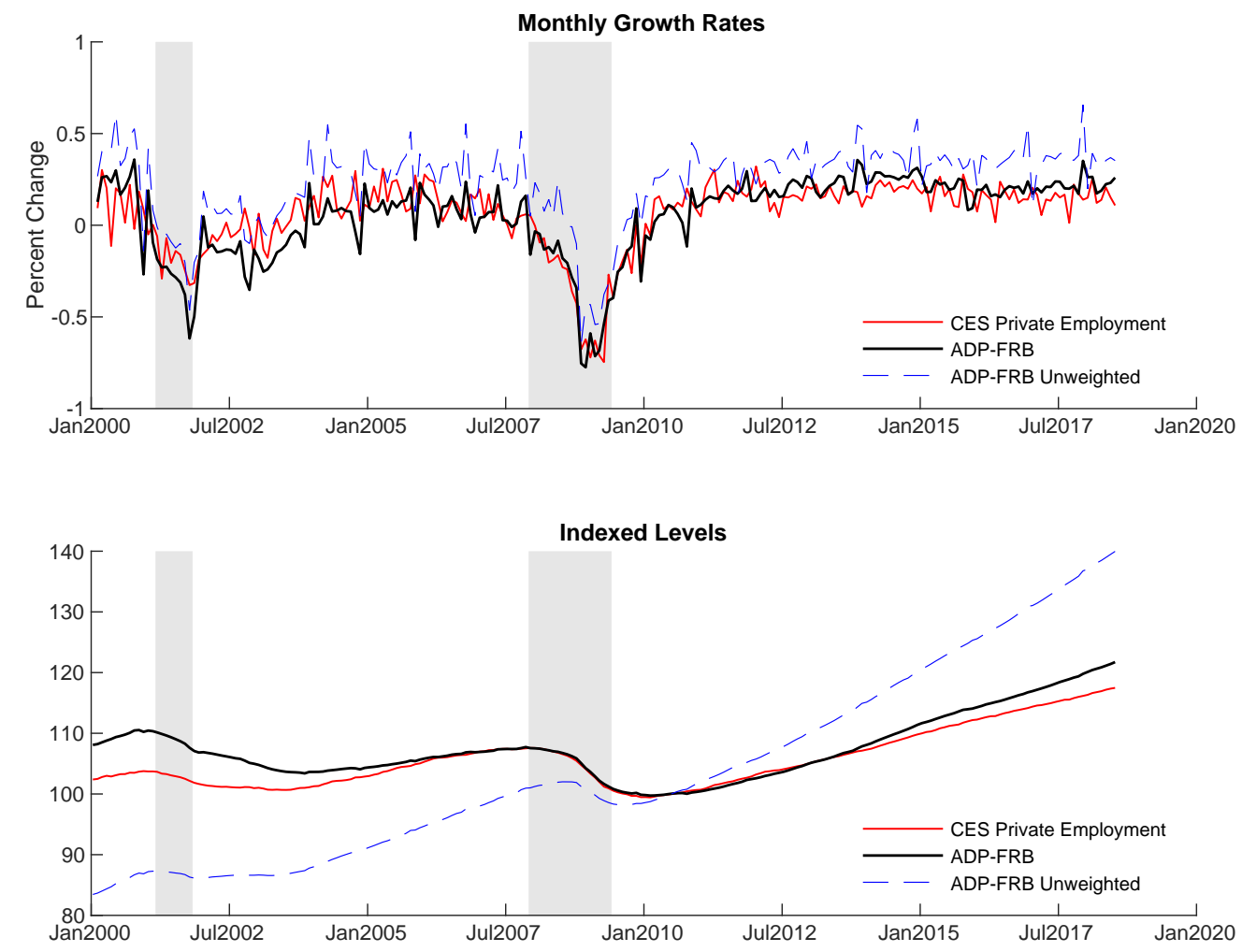

Note: Monthly data (current vintage), normalized to 100 in 2010.

Source: ADP, CES, authors' calculations. CES series is benchmarked; ADP-FRB is not.

Figure 1: Index Levels and Growth Rates

Both the ADP and the CES data are subject to dynamic selection issues related to establishment entry and exit. In the United States, young firms account for a disproportionate share of employment growth (Haltiwanger, Jarmin and Miranda, 2013); indeed, mean and median net employment growth rates of firms above age five tend to be around zero (Decker et al., 2014). A critical limitation of the CES sample is its lack of coverage of new firms and establishments. ${ }^{12}$ In addition, the CES does not directly measure establishment deaths. The BLS attempts to correct for these shortcomings using a two-step CES birth-death methodology. In the first step, employment losses from known business deaths are excluded from the sample to offset the missing employment gains from new business births. Thus, dead es-

\footnotetext{
${ }^{12}$ The CES sample is redrawn only once a year. See the CES technical notes at https://www.bls.gov/web/ empsit/cestn.htm.
} 
tablishments (i.e., those reporting zero employment) and nonrespondents (suspected dead establishments) are implicitly given the same growth rate as the continuing establishments in the CES survey. In the second step, an ARIMA model based on historical QCEW data estimates the birth/death residual: employment at newly formed establishments less employment at exiting establishments. This estimate is added to the estimates from the CES establishment sample to generate the final CES estimate. In many months, the model's contribution to headline employment estimates is sizable. ${ }^{13}$ Actual new firms do not affect CES estimates until the sample is rotated. ${ }^{14}$

Even after a benchmark revision, the monthly CES data never truly account for the birth and death of establishments. When a benchmark revision occurs, with the January CES release in a given year, the previous year's March level of the CES data is set to the March level of QCEW employment. The monthly sample-based estimates for the 11 months preceding the March benchmark are revised with the use of a "wedge-back" procedure, where a linear fraction of the benchmark revision is added to the CES level each month. ${ }^{15}$ The wedgingback procedure results in a constant being added to the monthly change in employment each year. So, while the year-to-year change in the post-benchmark CES data will capture the within-QCEW-scope dynamics of entry and exit at the annual frequency, the monthly numbers will not.

ADP suffers from a related limitation in that we do not know the age composition of ADP clients, nor do we observe firm or establishment age in the ADP microdata. However, new and young firms may enter the ADP data immediately upon engaging ADP for payroll

\footnotetext{
${ }^{13}$ See a discussion of the model and its recent contributions here: https://www. bls.gov/web/empsit/cesbd. htm. For example, since 2009 the net birth-death adjustment has added a nontrivial average of 800,000 jobs to a particular year's employment gains, or roughly 40 percent.

${ }^{14}$ The sampling frame is based on QCEW source data (state unemployment insurance (UI) records), which lag several months. It might be wondered if the UI records pick up new establishments quickly; this is apparently the case. Employers must file UI taxes if they have paid (cumulatively) $\$ 1,500$ or more in payroll, so most new employers would appear in the UI records very quickly; see https://oui.doleta.gov/unemploy/pdf/ uilawcompar/2018/coverage.pdf. However, note that even after a business birth appears in the UI records, there is also time required for sampling, contacting, and soliciting cooperation from the firm as well as verifying the initial data provided. In practice, CES cannot sample and begin to collect data from new firms until they are at least a year old; see https://www.bls.gov/web/empsit/cestn.htm.

${ }^{15}$ Again, see the CES technical notes.
} 
services. While the number of young firms in ADP data is unknown, any number could be a useful supplement to the CES data, in which new firms are entirely absent.

As discussed above, the ADP data consist of weekly snapshots (since July 2009). In contrast, the QCEW and CES data contain information for only the pay period that includes the 12th day of the month. As a result, the CES and QCEW data cannot measure employment activity over the entire month, which can be especially problematic in the case of temporary distorting events during the reference period. For example, an unusually large weather event (e.g., a hurricane or a snow storm) that reduced employment during the reference period but left the rest of the month unaffected would result in a CES employment report that understates the strength of the labor market throughout the month. In the weekly ADP data we can, in principle, observe both the shock and the recovery. In any case, averaging the level of employment for the month attenuates the impact of such short-lived events.

Finally, the QCEW and ADP data are both essentially administrative data and thus arguably somewhat less prone to reporting errors and nonresponse, which are often significant problems survey data such as the CES.

\section{Comparing ADP-FRB to Official Data}

\subsection{Predicting Annual Benchmarks}

In this section we evaluate the ability of ADP-FRB and CES to forecast the QCEW, which can plausibly be treated as "truth". We restrict attention to annual changes (March-to-March) to avoid complications related to seasonality and seam effects in the QCEW.

We follow the CES in benchmarking the level of our ADP-FRB indexes to the QCEW each year. Our procedure closely follows that of the CES: we iteratively force each March value of ADP-FRB to match the corresponding QCEW value, and we linearly wedge back the pre/post benchmark revision. The wedge reaches zero at the previous (already benchmarked) March. The data are currently benchmarked through March 2017. 
Throughout the paper, we use our monthly ADP-FRB index starting in 2007. For the purpose of annual benchmarking, this means we begin annual benchmark comparisons with the 2008 benchmark year, which measures the change in private nonfarm employment from April 2007 through March 2008. In the 10 years starting from 2008, the pre-benchmark ADPFRB estimates were closer to the eventually published population counts in four years, while the pre-benchmark CES estimates were more accurate in six years (see Table 1). Overall, the root-mean-squared benchmark revision is 0.49 percent for the ADP-FRB data and 0.36 percent for the CES data from 2008 onward. Interestingly, the ADP-FRB estimates markedly outperformed the CES estimates during the Great Recession (2008-2010). Specifically, from 2008 to 2010 the ADP-FRB absolute revisions averaged 200,000 per year, whereas the BLSCES absolute revisions averaged 490,000 per year. In contrast, over the past five years the pre-benchmark ADP-FRB estimates consistently overpredicted employment growth.

An evaluation of the CES benchmark misses should also take the net birth-death model into account, as the net birth-death adjustment adds roughly 40 percent to a particular year's employment change. As a result, a comparison of the benchmark misses of ADP-FRB series to the CES data is not exactly direct, as the ADP-FRB data would likely only capture a portion of the contribution of the employment contribution of births. The third row in Table 1 presents the benchmark miss of the CES data without the inclusion of the net birth-death adjustment. That is, the "CES no BD" row reflects the growth to the level of employment solely due to the sample of businesses for which the CES data is collected.

As can be seen in the table, the benchmark misses for CES excluding the net birth-death adjustment are substantially larger (with a root-mean-squared revision of 0.65 percent on average since 2008). Since 2008, the misses have also been almost always positive, reflecting a positive effect of establishments' births on the level of employment. The negative revisions in 2009 and 2010 point toward the autoregressive nature of the birth-death adjustment carrying inertia forward from previous years' employment changes. That is, because new business formation falls in recessionary years, the net effect of the birth-death frame- 


\begin{tabular}{l|rrrrrrrrrr}
\hline & 2008 & 2009 & 2010 & 2011 & 2012 & 2013 & 2014 & 2015 & 2016 & 2017 \\
\hline ADP-FRB & -173 & -451 & 12 & 709 & 283 & -230 & -1030 & -853 & -322 & -623 \\
CES & -137 & -933 & -391 & 229 & 481 & 340 & 105 & -259 & -151 & 136 \\
CES No BD & 645 & -216 & -55 & 561 & 972 & 975 & 874 & 638 & 737 & 1066 \\
\hline
\end{tabular}

Notes: Units: Thousands of jobs. CES revisions are the post-benchmark (QCEW-based) March estimate less the pre-benchmark estimate. ADP-FRB revisions are calculated in a similar fashion. CES no BD are the CES benchmark revisions that would have occurred excluding net birth-death adjustment.

Source: https://www.bls.gov/web/empsit/cesbmart.pdf, authors' calculations.

Table 1: Level Differences between Private Employment Benchmarks and Estimates

work overpredicts the actual birth-death contribution to employment growth, and thus CES benchmark misses were larger than benchmark misses of CES data with no birth-death adjustment.

We more formally test the performance of ADP-FRB and CES in predicting annual benchmarked employment growth by running the following regressions. The dependent variable is the annual change in employment from March of year $t-1$ to March of year $t$ as known upon the release of the CES benchmark revision in February of year $t+1$. We consider three different independent variables, with each annual observation specified as the econometrician observed them at the time of the CES jobs report for March of year $t$ : (1) annual employment change from March of $t-1$ to March of $t$ as estimated by monthly CES nonseasonally-adjusted figures; (2) estimated annual employment change from March of $t-1$ to March of $t$ as estimated by monthly CES non-seasonally-adjusted figures in which the contributions of the birth-death model have been removed; and (3) annual employment change from March of $t-1$ to March of $t$ as observed in the ADP-FRB non-seasonally-adjusted ("active") employment index. The purpose of the exercise is to evaluate the ability of an analyst to estimate "true" (i.e., benchmarked) employment gains for the past year, observed at the time of the CES March employment report (in early April). At that time, the analyst has in hand CES data for the first release of March of year $t$ (which includes the second release of February of year $t$ and the third release of January of year $t$ and all prior months). The analyst also has in hand the past year's ADP-FRB data up through the third week of March 
of year $t$. That is, we estimate the following:

$$
\Delta E M P_{t}^{B}=\alpha+\beta \Delta E M P_{t}^{M a r c h}+\varepsilon_{t}
$$

where $\triangle E M P_{t}$ is the change in private nonfarm employment from March of year $t-1$ to March of $t$, the $B$ superscript indicates the benchmark revision vintage of the series, the March superscript indicates the vintage of the series that is released with the March jobs report in year $t$ (where we construct the annual estimate by summing all non-seasonallyadjusted monthly estimates through the year), and $\triangle E M P_{t}^{M a r c h}$ can be the March vintage of CES, CES without birth-death model contributions, or ADP-FRB ("active") employment.

Table 2 reports results from this annual forecasting exercise. While we believe there is value in reporting this formal test, given the extremely small sample size the results are suggestive at best and should be treated with caution. That said, we find that the best predictor of benchmarked employment growth, according to both adjusted $R^{2}$ and RMSE, is the CES series that excludes birth-death model contributions (column 2). That is, the birth-death model does not appear to improve estimates of annual employment growth beyond the inclusion of a simple regression constant (compare columns 1 and 2). The ADP-FRB series (column 3) has predictive content but is outperformed by both CES series. However, we do find that adding the ADP-FRB series to the CES series that excludes birth-death contributions does improve forecasts (column 5). ${ }^{16}$

While the regression results in Table 2 are interesting, it is difficult to draw conclusions from such small-sample exercises. Moreover, ADP-FRB data are most valuable to policymakers if they increase our ability to understand recessions in real time; the predictive power of ADP-FRB during periods of steady, modest job growth is much less useful. We illustrate the point with a simple case study from the only recession in our ADP sample. ${ }^{17}$

Consider the beginning of the Great Recession. The NBER business cycle dating com-

\footnotetext{
${ }^{16}$ In unreported exercises, we find that, unsurprisingly, the results are highly sensitive to the specific time period included.

${ }^{17}$ ADP began taking snapshots on a semimonthly basis starting in May 2006.
} 


\begin{tabular}{lccccc} 
& $(1)$ & $(2)$ & $(3)$ & $(4)$ & $(5)$ \\
\hline \hline CES & $1.126^{* * *}$ & & & $1.104^{* * *}$ & \\
& $(0.0316)$ & & & $(0.142)$ & \\
CES excl. Birth-Death & & $1.154^{* * *}$ & & & $0.927^{* * *}$ \\
& & $(0.0235)$ & & & $(0.0847)$ \\
ADP-FRB & & & $0.976^{* * *}$ & 0.0197 & $0.199^{* *}$ \\
& & & $(0.0543)$ & $(0.121)$ & $(0.0818)$ \\
Constant & $-163.7^{*}$ & $604.5^{* * *}$ & -135.1 & $-163.6^{*}$ & $452.5^{* * *}$ \\
& $(76.93)$ & $(75.29)$ & $(172.8)$ & $(82.61)$ & $(79.37)$ \\
Observations & & & & & \\
R-squared & 10 & 10 & 10 & 10 & 10 \\
Adj. R-squared & 0.990 & 0.994 & 0.969 & 0.990 & 0.995 \\
RMSE & 0.989 & 0.993 & 0.965 & 0.988 & 0.994 \\
\hline
\end{tabular}

Notes: Dependent variable is benchmarked annual change in private nonfarm employment, March to March. Years 2008-2017. * ${ }^{* *}$, and ${ }^{* * *}$ indicate statistical significance at the $10 \%$, $5 \%$, and $1 \%$ levels, respectively. Robust standard errors in parentheses.

Table 2: Forecasting Annual Employment Changes

mittee identified December 2007 as the business cycle peak, but throughout 2008, economic data sent somewhat mixed signals about the deterioration of labor market conditions. CES data releases from throughout 2008 were revised substantially with the 2009 QCEW benchmark.

Figure 2 reports three payroll real time ADP-FRB and CES estimates of the level of employment, along with the final (current vintage) CES estimate. The heavy blue line is the final CES estimate, which shows employment losses of about 1.4 million jobs by August 2008. The red lines show each real-time vintage estimate for 2008: each end point represents a first-print estimate, and the thicker central line represents the estimate after a few monthly revisions (but before the benchmark revision). That is, following the line back from an endpoint in month $t$, the line reflects the path of employment as it would have been known to observers in month $t$ (including revisions up to that date). The black lines show the same set of real-time estimates for the ADP-FRB index. All of the real-time series have been normalized to equal the CES current vintage estimates in August 2008 to remove a level shift 


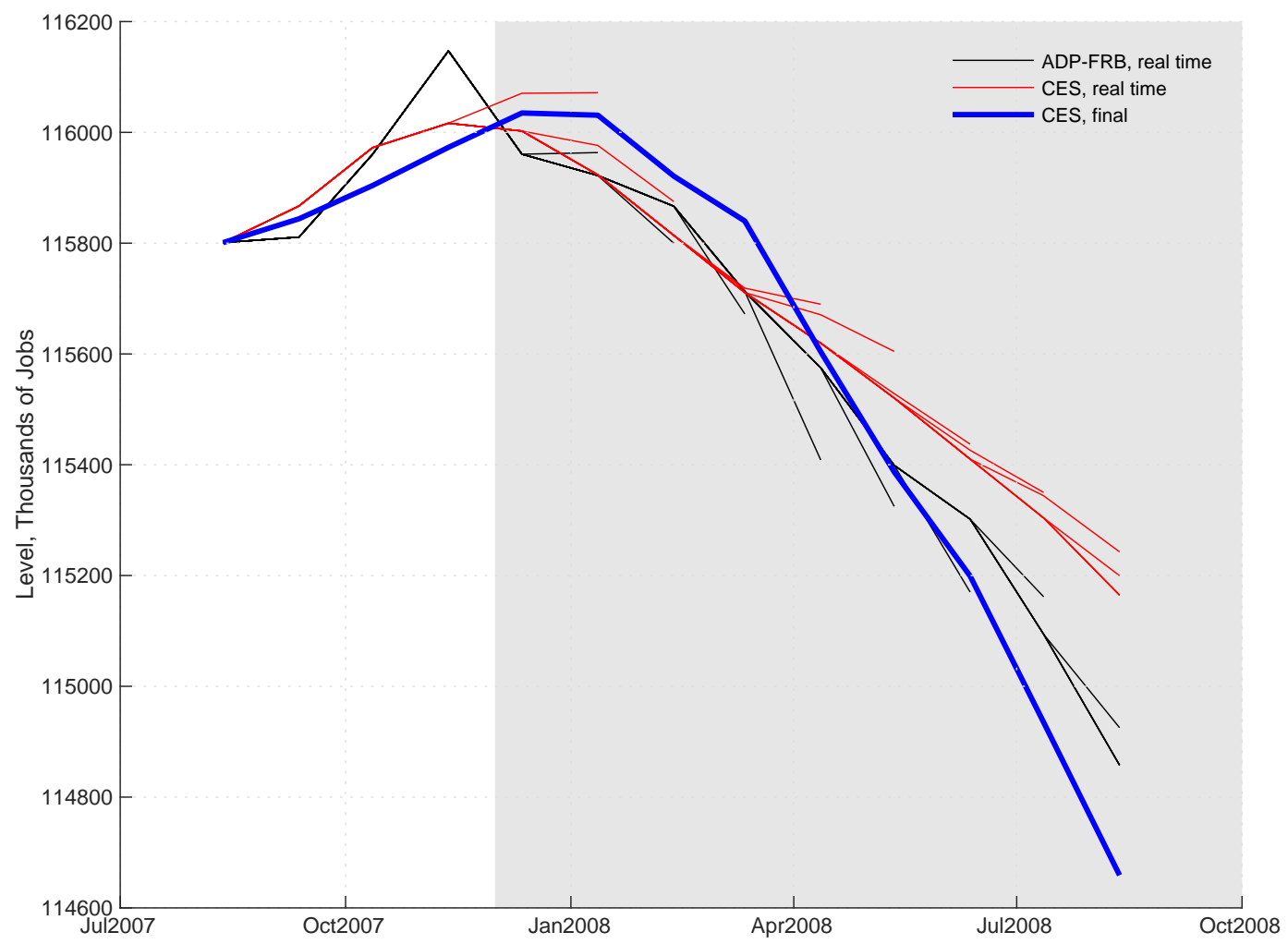

Note: Monthly data. NBER recession is shaded in gray. Real-time lines show each successive vintage as a connected line, with the end point at the first-print value for that month. All series have been normalized to match the current vintage CES estimate in August 2007.

Source: ADP, CES, authors' calculations.

Figure 2: Real-Time vs. Current Vintage Estimates

due to benchmark revisions.

As is apparent from the figure, in real time the ADP-FRB series was typically more accurate in tracking the true pace of labor market deterioration during the first year of the recession. By August, real-time CES estimates showed job losses totaling about 750,000, while ADP-FRB was at approximately 1.0 million job losses (both numbers should be compared with the current vintage estimate of 1.4 million job losses). Better knowledge of this deterioration would have been useful to policymakers as the critical fourth quarter of 2008 approached. In future cyclical downturns, ADP data may again prove useful in previewing the eventual revisions to CES data. 


\subsection{Predicting Monthly Employment}

While annual forecasts of the benchmark revisions are important, the CES is a monthly measure of employment that revises over several releases as both more data and benchmarks become available. In this section we evaluate the ability of the ADP-FRB employment indexes to improve forecasts of CES data in real time and in conjunction with other real-time indicators. Table 3 reports forecasting models described in Cajner et al. (2018) using realtime ADP indexes and other variables to predict the final print of CES (i.e., after all of the revisions). In particular, we estimated the following regression model:

$$
\Delta E M P_{t}^{C E S, \text { final }}=\alpha+\beta_{1} \Delta E M P_{t}^{A D P-F R B, R T 5}+\beta_{2} \Delta E M P_{t-1}^{C E S, R T}+\beta X_{t}+\omega_{t}
$$

The explanatory variables include current-month real-time (five weeks after the start of the month, which corresponds to the week before or the week of the Employment Situation release) ADP-FRB data, previous-month real-time (first print) CES private employment, as well as initial unemployment insurance claims, Michigan Survey unemployment expectations, the lagged (previous-month) unemployment rate change, and Bloomberg market CES payroll employment expectations. In addition, $\omega_{t}=\varepsilon_{t}+\rho \varepsilon_{t-1}$ is an $\mathrm{MA}(1)$ error term. ${ }^{18}$

Cajner et al. (2018) discuss similar results in more detail; here we simply note that the ADP-FRB indexes for active employment make statistically significant contributions to the model and generate modest improvements to forecasting accuracy. Column (1) of Table 3 reports the baseline forecasting model without the ADP-FRB data or market expectations. Adding market expectations in column (2) improves the forecast notably, as can be seen from the 15,000-job reduction in RMSE. In column (3) we add the ADP-FRB index and find that RMSE declines and the ADP-FRB coefficient is statistically significant; that is, the inclusion of the ADP-FRB index provides further marginal forecasting improvement beyond the inclusion of market expectations, in contrast to the Gregory and Zhu (2014) results us-

\footnotetext{
${ }^{18}$ The MA error term corrects for serial correlation in the errors when estimating equations of the change in employment. The results for a similar specification using OLS are qualitatively similar, despite the existence of serial correlation.
} 
(1)

\begin{tabular}{lccccc}
\hline \hline ADP-FRB active employment & & & $0.29^{* *}$ & $0.39^{* * *}$ & $0.16^{* *}$ \\
Lagged private CES employment & $0.82^{* * *}$ & -0.13 & -0.21 & $0.51^{* * *}$ & $(0.07)$ \\
& $(0.07)$ & $(0.15)$ & $(0.14)$ & $(0.12)$ & \\
Lagged UR change & $-156.73^{* *}$ & -45.66 & -43.05 & $-123.09^{* *}$ & \\
& $(61.56)$ & $(52.17)$ & $(46.84)$ & $(58.02)$ & \\
Unemployment expectations & $39.17^{* * *}$ & $30.95^{* * *}$ & 14.08 & 16.55 & 15.21 \\
& $(11.82)$ & $(11.01)$ & $(12.29)$ & $(12.74)$ & $(10.88)$ \\
Initial UI claims & $-3.10^{* * *}$ & -0.91 & -0.79 & $-2.52^{* * *}$ & -0.56 \\
& $(0.74)$ & $(0.71)$ & $(0.72)$ & $(0.83)$ & $(0.52)$ \\
CES employment expectations & & $1.15^{* * *}$ & $0.98^{* * *}$ & & \\
& & $(0.16)$ & $(0.15)$ & & $0.97^{* * *}$ \\
Private CES employment & & & & & $(3.07)$ \\
& & & & & \\
UR change & & & & & $(36.03)$ \\
Constant & 4.87 & $-17.77^{*}$ & $-24.39^{* *}$ & -7.48 & $-17.85^{* *}$ \\
& $(9.36)$ & $(10.40)$ & $(11.58)$ & $(10.77)$ & $(8.98)$ \\
RMSE & 99 & 84 & 80 & 92 & 58 \\
\hline
\end{tabular}

Notes: Dependent variable is final print of CES private employment. ADP-FRB series are real-time vintage, as of 5 weeks after the start of the month (i.e., the week before or week of the Employment Situation release). Unemployment expectations are from the Michigan survey. CES employment expectations are eve-of-release median markets expectations. Lagged private CES employment refers to pre-Employment Situation release. Robust standard errors in parentheses. RSMEs are calculated in-sample. ${ }^{*} p<0.10,{ }^{* *} p<0.05,{ }^{* * *} p<0.01$. Estimation period: $2007 \mathrm{~m} 1-2018 \mathrm{~m} 9$.

\section{Table 3: Forecasting Monthly Employment Changes}

ing ADP-NER. In column (4) we report a model including ADP-FRB but omitting market expectations, which reduces RMSE by 7,000 jobs relative to the baseline. Finally, column (5) indicates that even when the first print of CES data is available, the real-time ADP-FRB data provide additional signal about the final or "true" BLS measure of employment change.

The forecasting success of the ADP-FRB indexes should not be overstated. Cajner et al. (2018) show that the improvements in forecasting due to ADP data are statistically significant, though they are not particularly dramatic in magnitude. However, we should not expect dramatic improvement because the sampling variance of the CES estimate is large relative to the RMSE of our forecasts. For example, from 2013 until 2017 (which omits the Great Recession period of large forecast errors), the out-of-sample RMSE for predicting monthly 
payroll employment using the ADP-FRB data (along with other predictors) is 70,700 jobs, whereas the (sampling) standard error of the CES estimate is $65,000 .{ }^{19}$ To the extent that sampling error is i.i.d., the sampling error provides a lower bound on the forecasting error for CES estimates. Practically, it should be nearly impossible to reduce the RSME of a forecast below 65,000, and any forecast that achieved better performance would be forecasting sampling error, not actual changes in employment.

The fact that our forecasting errors are already close the 65,000 lower bound, even without the ADP indexes, suggests that the main value of the ADP data may not be in forecasting CES. The data can instead be used to generate estimates that are timelier, higher frequency, and more granular. In addition, the ADP data may be combined with the CES to reduce total measurement error.

On net, the ADP-FRB index adds to our understanding of annual and monthly employment changes and has some predictive power for benchmark revisions. Importantly, we find that during the Great Recession the ADP-FRB index provided a more accurate measure of the employment declines. With these findings in mind, we now turn to a methodology that combines the information from both the CES and the ADP-FRB series.

\section{State-Space Model of Employment}

Payroll employment growth is one of the most reliable business cycle indicators. Each postwar recession in the United States has been characterized by a year-on-year drop in payroll employment as measured by CES, and, outside of these recessionary declines, the year-onyear payroll employment growth has always been positive. Thus, if one knew the "true" underlying payroll employment growth, this would help enormously in assessing the state of the economy in real time. In this section, we present results from a state-space model to infer the "true" underlying payroll employment growth. ${ }^{20}$

\footnotetext{
${ }^{19}$ See https://www.bls.gov/web/empsit/cestn.htm

${ }^{20}$ Aruoba et al. (2016) use a similar approach to provide a better measure of output.
} 
Let $\triangle E M P_{t}^{U}$ denote the unobserved "true" change in private payroll employment (in thousands of jobs), which is assumed to follow an AR(1) process:

$$
\Delta E M P_{t}^{U}=\alpha+\rho \Delta E M P_{t-1}^{U}+\epsilon_{t}^{U}
$$

$\triangle E M P_{t}^{U}$ is a latent variable for which we have two observable noisy measures, that is CES $\left(\triangle E M P_{t}^{C E S}\right)$ and ADP-FRB $\left(\triangle E M P_{t}^{A D P-F R B}\right)$. Both are monthly changes in thousands of jobs. The observed values of CES and ADP-FRB employment gains are a function of the underlying state according to the following measurement equations:

$$
\left[\begin{array}{c}
\Delta E M P_{t}^{A D P-F R B} \\
\Delta E M P_{t}^{C E S}
\end{array}\right]=\left[\begin{array}{c}
\beta_{A D P-F R B} \\
\beta_{C E S}
\end{array}\right] \Delta E M P_{t}^{U}+\left[\begin{array}{c}
\epsilon_{t}^{A D P-F R B} \\
\epsilon_{t}^{C E S}
\end{array}\right] .
$$

Without loss of generality, we can assume that $\beta_{C E S}=1$. This assumption only normalizes the unobserved state variable to move one-for-one (on average) with CES. We make the assumption in our baseline specification but leave $\beta_{A D P-F R B}$ unrestricted. The latter approach is in contrast to Aruoba et al. (2013), who assume that both the observation variables in their paper (GDP and GDI) have unit loadings on the unobserved state variable. While those authors' assumption is justifiable given their use of the two well-understood (and conceptually equivalent) measures of output, given the relatively untested nature of the ADP-FRB data we feel it is better to let the model choose the loading.

We assume that all shocks are Gaussian and that $\epsilon_{t}^{U}$ is orthogonal to the observation errors $\left(\epsilon_{t}^{A D P-F R B}, \epsilon_{t}^{C E S}\right)$. However, we do allow the observation errors $\left(\epsilon_{t}^{A D P-F R B}, \epsilon_{t}^{C E S}\right)$ to be contemporaneously correlated, with variance-covariance matrix $\Sigma$ :

$$
\Sigma=\left[\begin{array}{cc}
\sigma_{A D P-F R B}^{2} & \sigma_{A D P-F R B, C E S}^{2} \\
\sigma_{A D P-F R B, C E S}^{2} & \sigma_{C E S}^{2}
\end{array}\right]
$$


Both the CES and ADP-FRB estimates can be regarded approximately as sample means, with the samples drawn from the same population. As such, both CES and ADP-FRB are (approximately) truth plus mean-zero sampling error. This sampling error is captured by the Kalman filter in the observation noise terms. A critical assumption for our setup is that this noise is i.i.d. over time, which would be exactly true if CES and ADP-FRB redrew their samples every month, but there is, in fact, much overlap in the units from one month to the next. Thus, any persistence in idiosyncratic establishment-level growth can propagate to persistence in the sampling error. Fortunately, the available evidence suggests that there is very low, or even negative, persistence in short-run establishment growth (Cooper, Haltiwanger and Willis, 2015), which in turn implies nearly i.i.d. sampling error and justifies the Kalman filter.

\subsection{Characterization of the State}

The estimates for the model above are collected in the first column of Table 4 . Interestingly, the estimate of $\beta_{A D P-F R B}$ is precisely estimated and not statistically different from unity. Somewhat surprisingly, the covariance of the observation errors $\sigma_{A D P-F R B, C E S}^{2}$ is negative, though it is not statistically different from zero. Specification 2 further generalizes the model, allowing for the ADP-FRB observation equation to have its own intercept $\alpha_{A D P-F R B}$. This modification makes little difference, and the point estimates are essentially unchanged from the baseline. Specification 3 imposes a unit factor loading in the ADP-FRB equation and a diagonal $\Sigma$. Again, these alterations do not significantly change the point estimates, though the variances of the observation errors are inflated somewhat. Finally, Specification 4 assumes that the unobserved state follows a random walk. All of the qualitative features of Specification 1 carry through to this model as well.

As discussed above, the BLS produces estimates of the sampling error of CES. These estimates are based on the observed cross-sectional variation in employment growth and knowledge of the stratified sampling scheme. The estimated standard error for the change 


\begin{tabular}{c|ccccc} 
& \multicolumn{5}{|c}{ Specification } \\
Parameter & $(1)$ & $(2)$ & $(3)$ & $(4)$ & $(5)$ \\
\hline \hline$\rho$ & $0.96^{* * *}$ & $0.96^{* * *}$ & $0.96^{* * *}$ & 1.00 & $0.96^{* * *}$ \\
$\alpha$ & $(0.02)$ & $(0.02)$ & $(0.02)$ & & $(0.02)$ \\
& 4.39 & 4.31 & 4.21 & 0.88 & 4.31 \\
$\beta_{C E S}$ & $(4.84)$ & $(4.84)$ & $(4.69)$ & $(5.03)$ & $(4.58)$ \\
& 1.00 & 1.00 & 1.00 & 1.00 & 1.00 \\
$\beta_{A D P-F R B}$ & $1.03^{* * *}$ & $1.03^{* * *}$ & 1.00 & $1.03^{* * *}$ & $1.06^{* * *}$ \\
\multirow{3}{*}{$\sigma_{U}^{2}$} & $(0.03)$ & $(0.03)$ & & $(0.03)$ & $(0.04)$ \\
& $3765.41^{* * *}$ & $3786.13^{* * *}$ & $3609.16^{* * *}$ & $3698.76^{* * *}$ & $3290.51^{* * *}$ \\
$\sigma_{C E S}^{2}$ & $(827.64)$ & $(832.95)$ & $(678.03)$ & $(805.89)$ & $(733.10)$ \\
& $3796.51^{* * *}$ & $3779.60^{* * *}$ & $3984.78^{* * *}$ & $3860.32^{* * *}$ & $4727.96^{* * *}$ \\
$\sigma_{C E S, A D P-F R B}^{2}$ & $(721.96)$ & $(721.17)$ & $(642.11)$ & $(713.98)$ & $(853.74)$ \\
$\sigma_{A D P-F R B}^{2}$ & -393.91 & -388.67 & & -315.56 & -869.32 \\
$\alpha_{A D P-F R B}$ & $(573.61)$ & $(573.63)$ & & $(563.56)$ & $(560.55)$ \\
& $3758.90^{* * *}$ & $3773.01^{* * *}$ & $4171.35^{* * *}$ & $3852.70^{* * *}$ & $3517.13^{* * *}$ \\
& $(792.63)$ & $(793.08)$ & $(680.98)$ & $(782.16)$ & $(761.84)$ \\
& & 4.10 & & &
\end{tabular}

Notes: Maximum likelihood parameter estimates. Measurement series are the monthly change in the number of jobs according to CES and ADP-FRB, in thousands of jobs. ${ }^{*}, * *$, and ${ }^{* * *}$ indicate statistical significance at the $10 \%, 5 \%$, and $1 \%$ levels, respectively. Standard errors are in parentheses. Specification 2 allows for a non-zero intercept in the ADP-FRB observation equation. Specification 3 restricts both observation equation loadings to unity, and assumes that the observation errors are uncorrelated. Specification 4 imposes a random walk on the unobserved state. Specification 5 uses an unbenchmarked version of the ADP-FRB series. Estimation period: 2006m5-2018m8.

\section{Table 4: Kalman Filter Parameter Estimates}

in private CES employment is about 65,000 jobs, which is remarkably close to our estimates of $\sigma_{C E S}$; the square root of $\sigma_{C E S}^{2}$ reported in Table 4 ranges between 61,000 and 69,000 jobs. In our state space model, $\sigma_{C E S}$ captures all sampling and non-sampling error in the CES series, so it is reassuring that our error estimates align so closely with those of the BLS.

Given that both the CES and the ADP-FRB series have been benchmarked to the QCEW, it may not be surprising that the model tends to treat them symmetrically. It is possible that most of the identification is coming from year-over-year variation, which would be dominated by the QCEW. We address this concern in Specification 5, which uses an unbenchmarked ADP-FRB series. The results are remarkably similar to the other specifications, in- 
dicating that the QCEW benchmark is not, in fact, dominating our estimates.

Taken together, the results in Table 4 suggest that is it reasonable to think of ADP-FRB and CES as two symmetric measurement series, each with approximately the same relation to the unobserved state (i.e., the same loading and intercept) and with approximately equal degrees of uncorrelated measurement error.

With these estimates in hand, we can extract estimates of the unobserved state process. Figure 3 shows the smoothed (two-sided) estimate of the state (the heavy black line), along with 90 percent confidence intervals (the gray shaded area). Naturally, the state estimate appears less volatile than either observation series. The smoothed state estimates use data for all available sample periods to estimate the state. A simpler exercise is also instructive. Following Mankiw, Runkle and Shapiro (1984) and Aruoba et al. (2013), we seek to approximate the state estimate using only contemporaneous observations of CES and ADP-FRB. In particular, let the estimator be

$$
\Delta E M P_{t}^{C}=\lambda \Delta E M P_{t}^{A D P-F R B}+(1-\lambda) \Delta E M P_{t}^{C E S}
$$

where $\lambda$ is the weighting parameter to be chosen. We minimize the distance between the state estimate and the weighted average:

$$
\min _{\lambda}\left\{\sum_{t=1}^{T}\left(\Delta \widehat{E M} P_{t}^{U}-\Delta E M P_{t}^{C}\right)^{2}\right\}
$$

where $\widehat{\triangle E M} P_{t}^{U}$ is the state estimate from the Kalman smoother. This exercise is particularly simple under the assumptions of Specification 3, where both series are just truth plus uncorrelated noise. In that case, we can plug in the estimated parameters and solve for $\lambda$ as

$$
\lambda^{*}=\frac{\widehat{\sigma_{C E S}^{2}}}{\widehat{\sigma_{A D P-F R B}^{2}}+\widehat{\sigma_{C E S}^{2}}},
$$




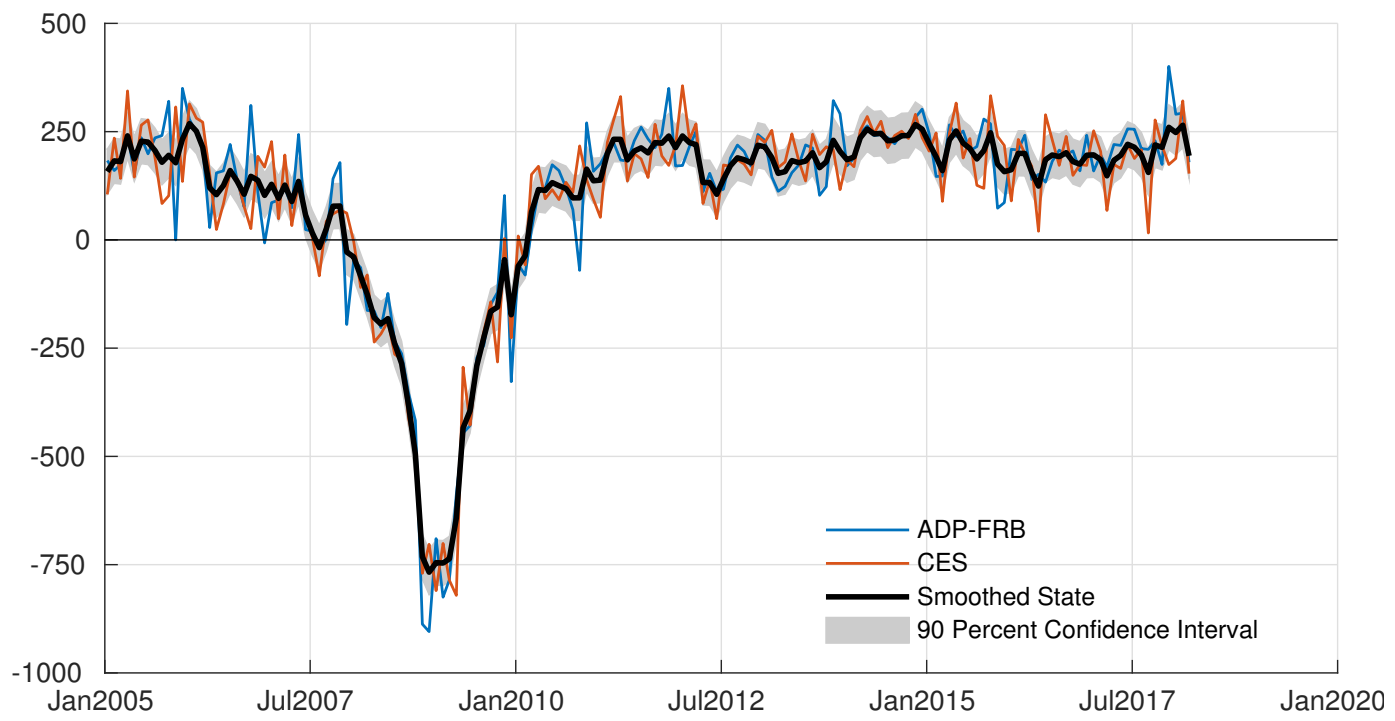

Note: Monthly data. Both CES and ADP-FRB are current vintage and benchmarked to QCEW. Smoothed state estimate is calculated from Specification 1.

Source: ADP, CES, authors' calculations.

Figure 3: Smoothed State Estimate

where $\widehat{\sigma_{C E S}^{2}}$ is the estimated variance of the observation error in CES, and similarly for $\widehat{\sigma_{A D P-F R B}^{2}}$. Using the values from Specification 3 yields $\lambda^{*}=0.49$, so the optimal contemporaneous estimator puts nearly equal weight on the two series. ${ }^{21}$ Relatedly, the Kalman gains for the two series (not shown) are also very similar.

Placing roughly equal weight on CES and ADP-FRB employment gains might seem counterintuitive. However, both data sets cover roughly a similar share of private U.S. payroll employment (23 percent for CES, 20 percent for ADP) and thus the sampling error could plausibly be of similar magnitude. Additionally, while the BLS eventually benchmarks CES payroll employment to the QCEW as discussed earlier, the month-to-month changes are largely unaffected by benchmarking due to the linear wedging-back procedure. Thus, if in a particular month the CES sample estimate of payroll employment gain is distorted because of the sampling error, it is likely that the error will survive even the subsequent revisions.

\footnotetext{
${ }^{21}$ Note that the linear combination of the ADP-FRB and CES series is nearly identical to the smoothed twosided state estimate from the Kalman filter.
} 
As the ADP data rely on a (mostly) different sample, it should be unsurprising that taking a Kalman filter estimate of underlying gains based on both observed measures should give a more precise estimate of the current pace of employment growth, with weights being roughly similar because of the similar sample size. ${ }^{22}$

\subsection{Evaluating the Estimated State's Predictive Content}

The fact that the CES and ADP-FRB series receive roughly equal weight when extracting the common signal supports the idea that combining the signal from both series can contribute to our understanding of "true" employment growth. In this section we tentatively treat the fully revised CES as "truth" and employ the state-space estimates to predict the future readings of final CES employment gains.

For the forecasting exercises, we employ a framework similar to that found in equation (2), without the additional controls. The dependent variable is the current vintage of the CES estimate. As independent variables we include various combinations of the ADP-FRB employment estimate, the CES employment estimate, the smoothed state as estimated using both ADP-FRB and CES, and the smoothed state as estimated by CES only. This final variable is included to distinguish the time-averaging effect of the state-space model from the additional information included in ADP-FRB. If the ADP-FRB series has no information, then CES and the smoothed state based on CES only ought to be the only relevant predictors. Importantly, all of the independent variables are real-time estimates, which means that the state-space estimates include no future information.

The results of this exercise can be found in Table 5. The first two columns include the $t+1$ current vintage CES employment value as its dependent variable. The second column adds the CES state as an additional explanatory variable. The third column contains the average employment growth over $t+1, t+2, t+3$-i.e., the average growth rate of the next

\footnotetext{
${ }^{22}$ In another exercise, we replace the ADP-FRB series with the change in employment calculated from the Current Population Survey (CPS), adjusted to the CES scope of private employment. We find that the optimal weighting only puts 4 percent of the weight on the CPS series, showing that near-equal weighting scheme for CES and ADP-FRB series was not an inevitable result.
} 
(1)

\begin{tabular}{l|ccc} 
& $\begin{array}{c}(1) \\
\text { CES employment }\end{array}$ & $\begin{array}{c}(2) \\
\text { CES employment }\end{array}$ & $\begin{array}{c}(3) \\
\text { 3-month average } \\
\text { CES employment }\end{array}$ \\
\hline \hline Constant & -28.14 & -28.52 & -17.05 \\
& $(19.43)$ & $(18.78)$ & $(20.35)$ \\
ADP-CES State & $1.43^{* * *}$ & $1.50^{* * *}$ & $1.69^{* * *}$ \\
ADP-FRB Emp. & $(0.49)$ & $(0.55)$ & $(0.44)$ \\
& -0.18 & -0.19 & $-0.30^{* *}$ \\
CES Emp. & $(0.15)$ & $(0.16)$ & $(0.15)$ \\
& -0.18 & -0.11 & -0.41 \\
CES State & $(0.34)$ & $(0.55)$ & $(0.31)$ \\
& & -0.12 & -0.04 \\
& & $(0.68)$ & $(0.42)$ \\
\hline
\end{tabular}

Notes: The dependent variable in columns 1 and 2 is the fully revised change in CES private employment at time $t+1$; in column 3 the dependent variable is the average of the fully revised change in CES private employment for $t+1, t+2$ and $t+3$. ADP-FRB series are real-time vintage, as of 5 weeks after the start of the month. CES series appearing as independent variable or in state-space estimates are real-time vintage. Robust standard errors in parentheses. ${ }^{*} \mathrm{p}<0.10,{ }^{* *} \mathrm{p}<0.05,{ }^{* * *} \mathrm{p}<0.01$. Estimation period: $2007 \mathrm{~m} 1-2018 \mathrm{~m} 9$.

Table 5: Forecasting Monthly Employment Changes using State Space Estimates

three months of employment. Estimated together, the only variable that is statistically significant across all three specifications is the ADP-CES state. ${ }^{23}$ The horserace results indicate that when comparing employment-based indicators of future CES readings of employment gains, the combination of the ADP-FRB series and the past CES gains provides the most information about future employment.

\section{Conclusion}

In this paper we asked whether additional information on payroll employment could improve the accuracy of employment estimates. We believe the answer is a qualified yes. At the monthly frequency, this question is tricky, as there is no "true" measure of monthly employment gains. ${ }^{24}$ That said, the ADP-FRB estimates and the resulting state-space measures

\footnotetext{
${ }^{23}$ In unreported results, we find that estimating each equation using only one of the explanatory variables indicates that each variable is independently significant. In addition, the horserace results are qualitatively similar when using first-print CES values as the dependent variable.

${ }^{24}$ As discussed above, the QCEW is more comprehensive than either CES or ADP-FRB, and serves as the annual benchmark for CES. However, the QCEW has measurement error and is not used as a time series by the
} 
that combine both the ADP-FRB and CES information provide insight into the current state and future values of employment. Moreover, we find that the monthly ADP-FRB estimates outperformed CES in tracking the rapid employment decline during the Great Recession and can help predict eventual revisions to the first prints of the CES data. At the annual frequency the official CES data best predict benchmark revisions, though the sample is small. That said, the ADP-FRB data were closer to the QCEW levels in four out of the past 10 years.

Could the BLS make use of data from payroll processors to supplement the CES? Our understanding is that ADP almost never reports any client firm employment numbers to BLS. The only exceptions are isolated cases where the client firm explicitly directs an ADP field office to submit their information for the CES survey. This being the case, the CES sample and the ADP sample are collected largely independently.

It is possible that improvements could be made through closer coordination. One possibility would be having payroll processors submit information to the BLS in a systematic way, which could allow for an increase in the sample size of CES, a reduction in collection costs, or both. BLS working directly with the payroll processors would reduce the burden on the sampled businesses. It could also reduce non-response, as businesses might be more willing to consent when they know their payroll company will handle the forms (even if the BLS obtains data directly from the processors, it would likely be necessary to obtain their consent). The per-unit cost to BLS of collecting data could also fall, as collection for more sample units would be handled through centralized payroll processors.

Such an arrangement may benefit the respondents and the BLS, but what incentive do the payroll processors have to take on the additional work? Civic duty may play some role, if processors see that a relatively low-cost contribution from them can measurably improve the national statistical framework. Payroll processors might also benefit from interaction with government statistical experts, who can suggest improvement and bring issues to their attention. Of course, payments may be necessary to get the cooperation of the processors. One approach would be allowing the sampled businesses to make a small payment to the BLS. See Groen (2012), Krueger and Fortson (2003), and Hiles (2016). 
payroll firm to avoid the survey paperwork. Another arrangement would have BLS paying the processor for access to the records, which would in turn raise significant "hold up" problems: if the BLS becomes dependent on payroll processor data, reducing or eliminating surveys, then the payroll processors would be free to raise prices once the outside option is gone. The relatively concentrated nature of the payroll industry means that competition for BLS contracts would be sparse, which suggests that agencies should not substitute private data for their own surveys, unless the market for the data is sufficiently competitive. While arranging for data collection through payroll processors may be challenging, we are actively exploring the possibilities.

The results in this paper lay the foundation for future work employing private payroll microdata. We plan on testing the estimated state-space results against other measures of employment, including state- and national-level measures of employment from the QCEW. We also plan on further exploring the geographic and industry detail to improve employment estimates. Importantly, there is additional information in the measure of ADP paid employment and at the weekly frequency that we have not fully leveraged in our current research.

\section{References}

Aladangady, Aditya, Shifrah Aron-Dine, Wendy E. Dunn, Laura Feiveson, Paul Lengermann, and Claudia Sahm. 2016. "The Effect of Hurricane Matthew on Consumer Spending." Board of Governors of the Federal Reserve System (U.S.) FEDS Notes.

Antenucci, Dolan, Michael Cafarella, Margaret Levenstein, Christopher Ré, and Matthew D. Shapiro. 2014. “Using Social Media to Measure Labor Market Flows.” NBER Working Paper 20010.

Aruoba, S. Borağan, Francis X. Diebold, Jeremy Nalewaik, Frank Schorfheide, and Dongho Song. 2013. “Improving U.S. GDP Measurement: A Forecast Combination Per- 
spective." In Recent Advances and Future Directions in Causality, Prediction, and Specification Analysis: Essays in Honor of Halbert L. White Jr. , ed. Xiaohong Chen and Norman R. Swanson, 1-25. Springer, New York.

Aruoba, S. Borağan, Francis X. Diebold, Jeremy Nalewaik, Frank Schorfheide, and Dongho Song. 2016. “Improving GDP Measurement: A Measurement-Error Perspective.” Journal of Econometrics, 191(2): 384-397.

Bernanke, Ben S., Jean Boivin, and Piotr Eliasz. 2005. "Measuring the Effects of Monetary Policy: A Factor-Augmented Vector Autoregressive (FAVAR) Approach." The Quarterly Journal of Economics, 120(1): 387-422.

Cajner, Tomaz, and David Ratner. 2016. "A Cautionary Note on the Help Wanted Online Data." Board of Governors of the Federal Reserve System (U.S.) FEDS Notes.

Cajner, Tomaz, Leland Crane, Ryan A. Decker, Adrian Hamins-Puertolas, Christopher Kurz, and Tyler Radler. 2018. “Using Payroll Processor Microdata to Measure Aggregate Labor Market Activity." Board of Governors of the Federal Reserve System (U.S.) FEDS Working Paper 2018-005.

Cavallo, Alberto, and Roberto Rigobon. 2016. "The Billion Prices Project: Using Online Prices for Measurement and Research." Journal of Economic Perspectives, 30(2): 151-178.

Cho, David. 2018. “The Labor Market Effects of Demand Shocks: Firm-Level Evidence from the Recovery Act." unpublished.

Cooper, Russell, John Haltiwanger, and Jonathan L. Willis. 2015. “Dynamics of Labor Demand: Evidence from Plant-Level Observations and Aggregate Implications." Research in Economics, 69(1): 37-50.

Decker, Ryan, John Haltiwanger, Ron Jarmin, and Javier Miranda. 2014. "The Role of Entrepreneurship in US Job Creation and Economic Dynamism." The Journal of Economic Perspectives, 28(3): 3-24. 
Gallin, Joshua H., Raven S. Molloy, Eric Nielsen, Paul A. Smith, and Kamila Sommer. 2018. “Measuring Aggregate Housing Wealth: New Insights from an Automated Valuation Model." Board of Governors of the Federal Reserve System (U.S.) FEDS Working Paper 2018-064.

Giannone, Domenico, Michele Lenza, and Giorgio E. Primiceri. 2017. “Economic Predictions with Big Data: The Illusion Of Sparsity." CEPR Discussion Paper 12256.

Goolsbee, Austan D., and Peter J Klenow. 2018. “Internet Rising, Prices Falling: Measuring Inflation in a World of E-Commerce." NBER Working Paper 24649.

Gregory, Allan W., and Hui Zhu. 2014. "Testing the Value of Lead Information in Forecasting Monthly Changes in Employment from the Bureau of Labor Statistics." Applied Financial Economics, 24(7): 505-514.

Grigsby, John, Erik Hurst, and Ahu Yildirmaz. 2019. “Aggregate Nominal Wage Adjustments: New Evidence from Administrative Payroll Data." NBER Working Paper 25628.

Groen, Jeffrey. 2012. "Sources of Error in Survey and Administrative Data: The Importance of Reporting Procedures." Journal of Official Statistics, 28: 173-198.

Haltiwanger, John, Ron S. Jarmin, and Javier Miranda. 2013. “Who Creates Jobs? Small versus Large versus Young." Review of Economics and Statistics, 95(2): 347-361.

Hatzius, Jan, Zach Pandl, Alex Phillips, David Mericle, Elad Pashtan, Dann Struyven, Karen Reichgott, and Avisha Thakkar. 2016. “The ADP Employment Report: Pay Attention to Large Surprises." Goldman Sachs Economics Research US Daily.

Hershbein, Brad, and Lisa B. Kahn. 2018. “Do Recessions Accelerate Routine-Biased Technological Change? Evidence from Vacancy Postings." American Economic Review, 108(7): 1737-72. 
Hiles, David. 2016. “QCEW Update: Acceleration Test and NAICS 2017." Bureau of Labor Statistics.

Kratzke, Diem-Tran. 2013. “Nonresponse Bias Analysis of Average Weekly Earnings in the Current Employment Statistics Survey." Bureau of Labor Statistics.

Krueger, Alan B., and Kenneth N. Fortson. 2003. “Do Markets Respond More to More Reliable Labor Market Data? A Test of Market Rationality." Journal of the European Economic Association, 1(4): 931-957.

Mankiw, N.Gregory, David E. Runkle, and Matthew D. Shapiro. 1984. “Are Preliminary Announcements of the Money Stock Rational Forecasts?" Journal of Monetary Economics, 14(1): $15-27$.

Ozimek, Adam, Dante DeAntonio, and Mark Zandi. 2017. "Aging and the Productivity Puzzle." unpublished.

Phillips, Keith R., and Christopher Slijk. 2015. “ADP Payroll Processing Data can Provide Early Look at Texas Job Growth." Southwest Economy, 10-13.

Stock, James H., and Mark W. Watson. 2002. "Forecasting Using Principal Components from a Large Number of Predictors." Journal of the American Statistical Association, 97(460): 1167-1179. 